\title{
La maternidad perfecta. La lactancia materna y sus expectativas
}

\author{
E. Panadero Utrilla ${ }^{a}$, E. Escribano Ceruelob, M. Duelos Marcos ${ }^{c}$ \\ -Psicólogo Residente (4. ${ }^{\circ}$ año). \\ ${ }^{b P e d i a t r a . ~ C S ~ B a r c e l o n a . ~ M o ́ s t o l e s, ~ M a d r i d . ~ E s p a n ̃ a . ~}$ \\ Pediatra. CS Guayaba. Madrid. España.
}

La maternidad perfecta. La lactancia materna ${ }^{1}$ y sus expectativas. Carta de una madre de un niño en su primer mes de vida:

"A lo largo de mi embarazo me he llevado varias decepciones para las que no te preparan en las clases de preparación al parto. En primer lugar, cuando me dijeron que no iba a poder tener un parto natural, ya que el niño estaba sentado y no se iba a poder dar la vuelta. En segundo lugar, cuando después del nacimiento de mi hijo, no tuve suficiente leche para alimentarle con el pecho.

Durante todo mi embarazo tuve muy claro que quería darle el pecho. En las clases de preparación nos repetían una y otra vez lo importante que era, te enseñan a darlo y te explican las propiedades, sus beneficios, etc. Pero para nada te pre- paran para las dificultades y el cómo afrontar el tema psicológicamente en caso de no poder hacerlo. Al igual que solamente te preparan para un parto natural y obvian en todo momento la posibilidad de una cesárea.

Por desgracia, mi niño tuvo complicaciones después de nacer y tuvo que estar en neonatos cuatro días. Estuve sin poder verlo durante 24 horas, tras las que empezó la odisea de darle el pecho. Cada tres horas iba a dárselo. Al principio, entre el dolor de la cesárea, el no saber y el tener a tres o cuatro personas diciéndote cómo hacerlo, las diferentes posturas, etc., entremetiéndose al tiempo..., me agobié bastante, aunque entendía que todo lo hacían por mi bien.

El niño se enganchaba al pecho, aunque se quedaba con mucha hambre y le 
tenían que dar biberón. Yo pensaba que esto se solucionaría cuando me diera la subida de leche, pero esto no ocurrió. Intenté todo lo que me dijeron en el hospital: le daba el pecho sin mirar la hora, cada vez que pedía, me sacaba la leche para vaciarla y producir más, me tomaba las pastillas Motilium, me daba masajes, me ponía calor, etc., y nada.

En casa fue de mal en peor, me levantaba angustiada ya por el día que tenía por delante. El niño se quedaba con hambre, lloraba y lloraba, y a mí me producía un gran desconsuelo. Siempre había querido darle pecho, y el hecho de no poder hacerlo era horrible. Me pasaba el día llorando. Con cada toma lo único que pensaba era en la siguiente, si tendría leche o no.

Algunas veces me salía algo de leche y otras sólo agua, y claro, cuando ocurría lo segundo no podía parar de llorar. Yo quería darle a mi hijo lo mejor y no podía, eso me producía una frustración que no me dejaba casi ni respirar.

El día era pecho, biberón y dormirle. Yo no podía dormir porque estaba obsesionada con la siguiente toma, y así día tras día. Por las mañanas era el peor momento del día, se me hacía cuesta arriba saber que tenía otras 24 horas por delante. No entendía porqué yo no podía alimentar al niño con el pecho.
Al principio pensé que era la bajada de hormonas, la gente me decía que duraría poco, hasta que nos asentáramos, que se me pasaría solo, pero yo llevaba ya casi dos semanas y la cosa iba a peor. Este sentimiento era un círculo vicioso, porque estar tan triste me producía un sentimiento de culpa -debía ser la más feliz del mundo por tener a mi hijo y sin embargo no lo era-, incluso llegué a pensar que estaba mejor trabajando. Me sentía mala madre. El niño estaba amarillo y no ganaba peso, con lo cual otra vez el sentimiento de culpa. Encima tenía que oír como todo el mundo opinaba y hacía comentarios como: '¿le darás pecho, no?, es lo mejor, date tiempo, ten paciencia', aparte de todos los consejos que te dan para darle el pecho y lo que tienes que comer y no comer para tener más leche. Sin contemplar en ningún momento que pueda ser alimentado de otra manera o como si tú pudieras elegirlo.

Lo peor es que yo no tenía ninguna razón objetiva para estar así. El niño estaba sano, tengo una familia y marido estupendos, y no podía evitar sentirme así y eso me mataba. Soy una persona racional y que me gusta controlar la situación, y no poder hacerlo me creaba todavía más angustia. Así que decidí escribir lo que me estaba pasando. Las razones objetivas y las subjetivas para estar así. En- 
tre las objetivas se encontraba que tenía que acostumbrarme, que el niño estuviera sano, podía decidir darle el pecho o no, mi marido era estupendo y ayudaba en todo. Entre las subjetivas se encontraban que me sentía mala madre, estaba agotada, lo del pecho me superaba, no soportaba estar sola, incluso sentía que prefería irme a trabajar que estar las 24 horas así.

Mi marido me decía que si tanto agobio me daba el tema del pecho, pues que se le daba el biberón y ya está, pero eso me hacía sentir todavía más culpable; ¿y si se lo quitaba y le pasaba algo mi hijo?, ¿y si cogía una bronquitis por mi culpa?

Yo no quería ver a nadie, ni que nadie viniera a casa, a excepción de la familia más cercana, ni amigos, ni primos ni nadie. No me arreglaba, tenía la cara hinchada, casi no comía, no hablaba con nadie y no tenía ganas de hacer nada. Prácticamente no salía, solamente me dedicaba a contar los minutos que quedaban para la siguiente toma. No le dejaba llorar, porque me decían que era peor, que cuando estuviera despierto le diera de mamar, así lo hacía, me decían que no le dejara más de tres horas y yo me ponía el despertador durante todo el día para que no se me pasara, etc.

La verdad es que si yo tuviera que decir qué ha sido lo peor del embarazo y el posparto, sin duda esos 20 días que estuve así; lo pase fatal, peor que con el embarazo, la cesárea, etc. El no ser capaz de disfrutar de mi hijo y de ese momento tan bonito.

Solo espero que se me vaya olvidando, para tener ganas de tener otro niño y pensar que esto no tiene porqué volver a ocurrir."

\section{Comentarios a la carta}

Tener hijos es algo natural y son muchas las voces que abogan porque así sea, pero también es un proceso de cambio y los cambios cuestan.

Cada uno de los pasos puede resultar sencillo, pero esto no es cierto. La vida de las mujeres se ha vuelto más difícil: quedarse embarazada en el momento en que ambos padres lo desean, que el embarazo no sea molesto, un parto natural y un bebé que permita dormir. Puede que a los padres no les cueste adaptarse a ser tres, y que las familias respectivas sepan apoyar respetando la intimidad y sin descalificar a los nuevos padres.

Pero también pueden surgir complicaciones (no queremos hablar aquí de grandes tragedias, sino de pequeñas cosas que no salen como "deberían"). El embarazo no viene en el mejor momento y este es molesto, el parto se adelanta o es necesario hacer una cesárea. El niño pue- 
de no ser un "angelito": duerme mal, llora constantemente o le cuesta engancharse al pecho (como en la carta que nos escribe esta madre).

¿Por qué a los profesionales nos cuesta tanto aceptar esto?, ¿por qué no hablamos de estas dificultades como algo natural, algo que puede pasar y pasa con relativa frecuencia? La preocupación por estas posibles complicaciones es tan natural que aparece en la mayoría de las embarazadas en el tercer trimestre, seguramente como un mecanismo para estar preparadas.

Damos a los futuros padres un modelo de paternidad digno de un anuncio de televisión, donde todo es bonito y perfecto. Al negar que puede ser complicado este proceso les hacemos ver que si todo no es idílico es que son malos padres.

Winnicott ${ }^{2}$ afirmó que el objetivo no era ser un padre perfecto, sino lo suficientemente bueno: ver lo que tu hijo necesita e intentar adaptarte a ello con los recursos que tengas.
Hablemos y dejemos a los padres tener miedos, "odiar" al bebé a ratos, equivocarse, etc., porque de todos modos va a ocurrir y está bien que suceda para que ambos padres y el bebé puedan adaptarse los unos a los otros ${ }^{3}$.

Al mismo tiempo, y como dice la autora francesa Elisabeth Badinter en su último libro ${ }^{4}$, sintámonos felices de eximir a las mujeres del sentimiento de culpa, yendo contracorriente, contra el instinto maternal que tanto las transforma en víctimas. Defendamos a la mujer de ser la madre perfecta.

Para concluir, y enlazando con la carta de esta madre, a veces la lactancia materna no va a ser posible, y negándolo y culpando a la madre no contribuiremos a que se logre; y sin duda crearemos un dolor innecesario. La lactancia debe ser nutricia también a nivel emocional y la culpa no la favorece.

Agradedecemos a Verónica, madre de Eduardo, la autorización para publicar su carta.

\section{Bibliografía}

1. Agostoni $C$, Braegger $C$, Decsi $T$, Kolacek $S$, Koletzko B, Michaelsen KF et al. Breast-feeding: A commentary by the ESPGHAN Committee on Nutrition. J Pediatr Gastroenterol Nutr. 2009;49: 112-25.
2. Winnicott $D$. La teoría de la relación paterno filial. Los procesos de maduración y el ambiente facilitador. Buenos Aires: Paidós; 1992.

3. Bowlby J. The nature of the child's tie to his mother. Int J Psychoanal. 1958;39:350-73.

4. Badinter E. Le Conflit: la femme et la mère. París: Flammarion; 2010. 